\title{
Е.Ю. Федотова
}

\section{ПОСТИЖЕНИЕ ФЕНОМЕНА МОЛЧАНИЕ: ВИТГЕНШТЕЙН И ВОСТОЧНАЯ ФИЛОСОФИЯ}

\begin{abstract}
Проводится компаративный анализ философии Людвига Витгенштейна и восточных философских традиций в отношении к осмыслению феномена молчание. Автор статьи предлагает рассмотреть поставленную проблему в трех основных аспектах: 1) понимание философии как деятельности; 2) обособление показывания как третьего способа коммуникации; 3) понимание молчания в контексте витгенштейновской и восточной философской мыссли.

Ключевые слова: Витгенштейн, восточная философия, молчание, компаративный анализ.
\end{abstract}

Проблема взаимодействия языка и мира всегда вызывала интерес как в западной, так и в восточной философии. В частности, особое внимание попрежнему уделяется молчанию, представляющему собой специфическую категорию языка. В мировой философии можно обнаружить множество идей осмысления феномена молчания, однако, на наш взгляд, наиболее результативной представляется идея сопоставления видений двух философских систем, принадлежащих к разным культурным традициям и способам мышления. В данной статье предлагается проанализировать феномен молчания в творчестве выдающегося западного философа Людвига Витгенштейна и в восточной философии: даосизме и буддизме. Приступая к компаративному анализу разных философских традиций, в рассматриваемом случае относящихся к культурам Запада и Востока, следует обратить внимание на необходимость выявления как сходств, так и различий между исследуемыми философскими системами.

Следует отметить, что проблема сравнения творческого наследия Витгенштейна и восточных философских систем не получила широкого освещения в отечественной литературе и представлена единичными публикациями, наиболее значимыми из которых, на наш взгляд, являются «Витгенштейн и дзен-буддизм» М.С. Козловой и «Деятельность с умом, очищенным от мысли? (Л. Витгенштейн и восточная философия)» Т.Н. Панченко, где сопоставляются различные аспекты витгенштейновской и восточной философской мысли. Среди исследований зарубежных ученых, проведенных в обозначенной сфере, можно выделить следующие: «Чань-буддизм, даосизм и Витгенштейн» Т. Томинага, «Дзен Витгенштейна» С. Макграта, «Хайдеггер и Витгенгтейн: поэтика молчания» С. Биндемана, в котором анализируется специфика категории молчания в философии Витгенштейна, и др.

Сопоставляя европейскую философию и неевропейские философские традиции, А.В. Горин указывает, что «наиболее плодотворно оказывается сравнивать не содержания (понятия), а проблемные поля и движимые ими стратегии мысли, методы» [1. С. 58]. Однако для того, чтобы адекватно опре- 
делить область предстоящего анализа, следует обозначить и прояснить ключевые категории исследуемых философских систем, которыми необходимо оперировать при проведении сопоставительного анализа, так как это даёт возможность построения целостной картины исследования. В рамках данного исследования предполагается сопоставить философское понимание языка и определение природы молчания в творчестве Людвига Витгенштейна и восточных философских системах даосизма и буддизма в нескольких аспектах. В первую очередь анализируется понимание философии не как теории, а как деятельности. Такой подход характерен как для Витгенштейна, так и для восточных философских практик. При этом следует особое внимание уделить осмыслению роли языка в контексте такой деятельности. Вторым ключевым аспектом данного исследования является определение показывания как способа общения, отличного от говорения и молчания, и выявление характерных особенностей данной категории в философии Витгенштейна и философских системах даосизма и буддизма. Третий раздел посвящен специфике осмысления феномена молчания в контексте витгенштейновской и восточной философской мысли.

\section{1. Философия как деятельность}

В начале XX столетия видные представители западной культуры и философии отправились в «паломничество на Восток» [2. С. 139]. Но ничего не известно о наличии достоверных доказательств того, вступил ли в их ряды Витгенштейн. Не представляется возможным с уверенностью сказать, что какие-либо конкретные восточные философские школы оказали непосредственное влияние на становление его философии. Тем не менее неоспоримым является тот факт, что, несмотря на очевидные культурные различия Запада и Востока, многие исследователи отмечают явные сходства между творческим наследием Витгенштейна и восточными философскими учениями. Чаще всего философию Витгенштейна сравнивают с даосизмом и буддизмом, где последний представлен преимущественно японским дзен-буддизмом. Важно отметить, что сам термин «дзен» происходит из санскритского понятия «дхьяна» и китайского «чань». Данные категории имеют значение «сосредоточения духа в молчании» [3. Р. 38]. Исходя из этого определения, дзенбуддизм, сформированный при сильном влиянии даосизма, следует рассматривать не как некую доктрину или догму, но как практику. В этом аспекте наблюдаются определённые сходства с философией Витгенштейна, утверждающего, что философия это «не учение, а деятельность» (4.112) [4. С. 24].

Согласно раннему Витгенштейну, философия как деятельность «состоит из разъяснений», а её цель представляет собой «логическое прояснение мыслей» [4. С. 24]. По существу, любое разъяснение - это разъяснение на языке. В этом отношении философия должна позаботиться о соответствующем языке, который был бы способен логически прояснить мышление. В «Трактате» Витгенштейн указывает: «Мысль - осмысленное предложение» (4) [4. С. 18]. Следовательно, философия представляет собой критику языка - такую деятельность, которая позволяет обнаруживать или определять смысл предложений. 
Необходимо отметить, что поздний Витгенштейн придаёт философии несколько иное - терапевтическое - значение. Если цель философии, согласно раннему Витгенштейну, заключается в логическом прояснении мыслей, то цель «терапевтической» философии «состоит в том, чтобы избавиться от недоразумений относительно используемых слов» [5. С. 26]. Утратив в своём философствовании оттенок мистицизма, присущий «Трактату», Витгенштейн сближается с позицией дзен-буддизма в том, что процессу коммуникации зачастую свойственна путаница при использовании понятий в контексте тех или иных ситуаций; человеческий разум склонен заблуждаться. Следовательно, философия как деятельность превращается в борьбу «против зачаровывания нашего интеллекта средствами нашего языка» (§ 109) [4. С. 127]. Иными словами, «Витгенштейн следует пути дзен-буддизма» [3. Р. 41], с той лишь разницей, что в философии Витгенштейна понимание деятельности неразрывно связано с функционированием языка.

В восточной философии картина соотношения языка и деятельности выглядит несколько иначе, нежели витгенштейновская. Очевидно, что практическая сторона философии буддизма не представляет значительных сложностей для восприятия на Западе. Более того, буддизм приобрёл статус не просто особенной экзотической, но «аналитической религии» [6. С. 21]. Но само восприятие языка в традиции восточных философских учений имеет свои нюансы. Отношение к языку, в частности к говорению посредством слов, в большинстве случаев носит негативный оттенок. В буддизме язык часто рассматривается как препятствие на пути к просветлению. Ведь став просветлённым, достигнув заветной цели - нирваны, - Будда погрузился в «благородное молчание». Будда никогда прямо не отвечал на вопрос, что же такое нирвана: он старался хранить молчание. Е.А. Торчинов отмечает, что в данном случае «Будда оказывается прямым предшественником знаменитого философа XX в. Л. Витгенштейна, провозгласившего: о чем нельзя говорить, о том следует молчать» [7. С. 45]. В этом отношении американский исследователь буддийской философии М. Д’Амато указывает на то, что «в языке и концептуализации коренятся проблемы разумного существования; язык и концептуализация представляют собой основные причины страдания разумных существ» [8. Р. 41-42]. В итоге получается, что необходимым условием избавления от страданий и достижения просветления является отказ от языка в пользу молчания.

\section{2. Показывание как «третий способ» коммуникации}

Таким образом, именно молчание занимает приоритетное, по отношению к языку, положение в восточных философских практиках. Но, с другой стороны, если язык мешает достичь просветления и от него необходимо отречься, то возникает вопрос: каким образом возможно понять опыт просветления и описать его сущность, если сам язык не может быть использован для этих целей? Ответ на этот вопрос заключается в том, что помимо языка и молчания существует «Третий способ» коммуникации, который известный буддолог Г. Чанг описывает следующим образом: «Третий способ заключается в описании посредством прямого “указывания" или показывания. Иностранный студент спросил преподавателя английского языка: "What is a table?" Ho 
вместо того, чтобы рассказать, что стол представляет собой разновидность мебели, состоящей из плоской доски и стоящей на ножках, преподаватель ударил кулаком по столу напротив него и произнёс: “This is a table!” Это пример прямого показывания. Никакого объяснения или понятия здесь не требуется» [9. Р. 63]. Кроме того, дзен-буддийские философы выступают против критикуемой поздним (но разделяемой ранним) Витгенштейном «августинианской» концепции языка, согласно которой конкретное понятие соответствует определённому предмету. Философы-буддисты подчёркивают тот факт, что язык является лишь «пальцем, указывающим на луну, но не самой луной» [3. Р. 40]. Иными словами, следует смотреть не на палец, а на то, на что этот палец указывает. Как в философии Витгенштейна, так и в буддизме, смысл не может быть сказан, а только показан.

Здесь следует отметить, что показывание в философии Витгенштейна можно рассмотреть с двух позиций. С одной стороны, он рассматривает показывание как элемент изобразительной (picture) или, как ее ещё называют, пиктографической теории предложений - теории, согласно которой предложения являются картинами той реальности, которую они описывают [10. Р. 119]. Для раннего Витгенштейна «все предложения повседневного языка являются “картинами”, описывающими ту, или иную ситуацию в логическом пространстве» [5. С. 46]. Эта идея Витгенштейна заключает в себе представление, что логические предложения являются основными носителями смысла. «Предложение показывает логическую форму действительности. Оно предъявляет ее» [4. С. 25]. Логическая форма, в свою очередь, в «Трактате» представлена «важнейшим условием репрезентации и коммуникации» [11. С. 65]. Также Н.В. Медведев подчёркивает, что «через логическую форму репрезентируются все наши знания о фактах действительности, но саму эту форму выразить невозможно: она лишь показывает себя» [11. С. 65-66]. Однако впоследствии изобразительная теория предложений, потребность в которой казалась очевидной в «Трактате», была подвергнута критике самим Витгенштейном в его поздних работах. Наиболее полное ее переосмысление отображено в «Философских исследованиях» (1953).

С другой стороны, ряд исследователей отмечают, что категория показывание выступает как способ коммуникации. В качестве примера можно привести позицию румынского исследователя Ш. Влэдуцэску, который указывает, что Витгенштейн между говорением и языковым молчанием помещает показывание: то, что не может быть сказано, «показывает себя» (6.522) [4. C. 72]. В качестве примера он приводит взгляд, который не относится ни к сфере говорения, ни к области молчания [12. Р. 83]. Взгляд не молчит, но и не располагается в логическом пространстве: он показывает. Кроме того, Н.В. Медведев в своём исследовании отмечает, что Витгенштейн «рассматривает возможность человеческой коммуникации без артикулированной речи или письма, построенной на одних лишь жестах, мимике, осуществляемом на довербальном уровне понимания» [5. С. 64]. Таким образом, показывание не принадлежит молчанию, но вместе с тем не является актом осмысленного говорения. Показывание не молчит, тем не менее его нельзя назвать логическим. Не располагаясь в логическом пространстве, показывание не побуждает к молчанию. Следовательно, все то, что не может быть сказано, может быть 
показано. В результате, показывание является ключевым элементом выражения мысли, наравне с говорением и молчанием, что справедливо как для философской мысли Востока, так и для философии Витгенштейна.

\section{3. «О чём невозможно говорить, о том следует молчать»}

Молчание занимает особое место в творчестве Витгенштейна. Седьмой тезис «Трактата»: «О чём невозможно говорить, о том следует молчать» (7) [4. С. 73] - не является неким обособленным или случайным утверждением Витгенштейна, по сути - это логическое завершение основной идеи его труда. Ещё в предисловии к «Трактату» он подчёркивает: «Смысл книги в целом можно сформулировать приблизительно так: то, что вообще может быть сказано, может быть сказано ясно, о том же, что сказать невозможно, следует молчать» [4. С. 3]. Ключевым моментом в понимании такого молчания следует считать не отсутствие звука, так как это не простое безмолвие, лишенное мысли, но отсутствие осмысленного произнесения слов вслух, т.е. отсутствие логически правильного говорения. Н. Гарвер в своей работе обращает внимание на то, что «так же как говорение включает в себя не только произнесение слов, молчание представляет собой не просто отсутствие звука» [13. P. 68]. То, что может быть сказано, согласно Витгенштейну, должно иметь смысл. Это означает, что сказанное, вне зависимости от того, является оно истинным или ложным, может быть разъяснено логически. Таким образом, бессмысленно все то, что не может являться однозначно истинным или ложным. Противоречия не могут быть истиной, равно как и тавтологии не могут быть ложью: они ничего не говорят о фактах мира и, следовательно, лишены смысла.

В восточных философских традициях молчанию придаётся несколько иное значение. Здесь наблюдается явное недоверие к передаче знаний от одного человека другому посредством слов. В конечном итоге это приводит к «превозношению молчания». Т.Н. Панченко определяет отношение последователей буддизма и даосизма к использованию языка и молчания в коммуникативных целях следующим образом: «Молчание как истинная форма коммуникации противопоставляется ими обыденной коммуникации посредством слов» [2. С. 141]. В своё время, на много столетий ранее, чем Витгенштейн, Лао-цзы достиг пределов языка. Это способствовало его осознанию того, что возможно «управлять ситуацией без действия и “осуществлять учение, не прибегая к словам"» [2. С. 147]. Т.Н. Панченко, указывая на то, что философ может учить без слов, показывая, служа примером собственных ценностей, предполагает, что, может быть, то же самое имеет в виду и Витгенштейн, когда говорит, что следует молчать о том, о чём невозможно говорить [2. С. 147].

Однако у Витгенштейна наблюдается явное отличие от восточных философских учений в том, что он подразумевает под молчанием прежде всего отсутствие логически верного высказывания. Как подчеркивает Н. Гарвер, неверно употребленные подобным образом слова не имеют смысла «даже если они будут не только произнесены, но 〈..> если мы прокричим их с крыши. Выкрикивание ни о чем не говорит» [13. Р. 68]. Из этого следует, что в данном контексте даже выкрикивание мы можем отнести к некой форме молчания, так как оно не располагается в логическом пространстве. Безус- 
ловно, роль, которую молчание играет в философии раннего Витгенштейна, не менее значима, чем в буддизме или даосизме. Но она иная. Т. Томинага подчёркивает, что ранний Витгенштейн «предназначает молчанию роль логического индикатора, который сообщает, когда достигаются пределы языка», тогда как в буддизме и даосизме «молчание действует как онтологическая предпосылка возможности языка, а не как следствие, диктуемое невозможностью речи» [14. Р. 141]. В этом аспекте наблюдается уже сходство восточных философских традиций с философией Мартина Хайдеггера, определявшего молчание в качестве истока речи.

Следует отметить, что, пересмотрев многие положения своей философии раннего периода, поздний Витгенштейн, по сути, не разработал новой концепции языка, но он продолжил в «Философских исследованиях» (1953) анализ повседневного языка, представляющего один из компонентов молчания в соответствии с «Трактатом». Молчание определяется как место для языковых игр, в которых значение слова дано через его употребление в говорении. Таким образом, молчание у Витгенштейна позднего периода по большей части утратило мистический оттенок, роднящий его творчество с восточной философией. Но взамен старым сходствам философская мысль Витгенштейна приобрела новые сходства с философией даосизма и буддизма, которых ранее не наблюдалось. Прежде всего, это терапевтическое понимание философии. Витгенштейн указывает, что «пожалуй, нет какого-то одного метода философии, а есть методы наподобие различных терапий» (§133) [4. С. 132]. Так и буддизм, отвергая какой-либо установленный и признанный философский метод, выражаясь словами Витгенштейна, ведёт борьбу «против зачаровывания нашего интеллекта средствами нашего языка». Исходя из того, что «Философские исследования» и философские учения Востока не являются тождественными друг другу, их сопоставительный анализ способствует более глубокому пониманию некоторых ключевых моментов осмысления феномена молчания в их философских системах.

\section{Заключение}

Сравнение творчества Витгенштейна с восточной философией способствует некоторому прояснению его сложной философской системы. Необходимость такого прояснения результатов напряжённой работы его мысли обусловливается тем фактом, что философия Витгенштейна оказала и продолжает оказывать столь сильное влияние не только на современную западную, но и восточную философию.

Несмотря на очевидные различия в двух философских системах, не представляет трудности обнаружить явные сходства в философии Витгенштейна и восточных философских практиках. Прежде всего, они заключаются в том, что философия - это реализуемая на практике деятельность, но не догма или теоретическое учение. Цель философии Витгенштейна, заключающаяся в критике языка и, как следствие, логическом прояснении мыслей, созвучна с устремлением даосизма и буддизма к прояснению деятельности ума на пути к достижению просветления. Однако если у Витгенштейна деятельность философии непосредственно связана с функционированием языка - это либо логическое прояснение мыслей, согласно раннему периоду творчества, либо 
«терапия» в поздний период, то даосизм и буддизм вообще не доверяют языку как коммуникативному инструменту для передачи знаний и опыта, предпочитая ему молчание. Так или иначе, Витгенштейн и восточные философские учения сходятся в том, что существует нечто, невыразимое посредством слов. Данная проблема решается при помощи третьего способа коммуникации - показывания, не относящегося ни к говорению, ни к молчанию.

Молчание играет значимую роль как для Витгенштейна, так и для восточной философии. Эти два способа практики молчания, не являясь по существу тождественными, дополняют друг друга. Таким образом, философия Витгенштейна не только демонстрирует явное сходство с мыслью восточных философских практик, но она также может быть осмыслена как способствующая их пониманию. Равно как и наоборот: понимание даосизма и буддизма может оказать значительную помощь в достижении более полного представления о философии Витгенштейна.

\section{Лuтература}

1. Горин А.В. Границы языка и язык границ. Витгенштейн и дзэн // Путь Востока. Проблема методов. Материалы IV Молодежной научной конференции по проблемам философии, религии, культуры Востока. Серия “Symposium”, выпуск 10. СПб.: Санкт-Петербургское философское общество, 2001. С.57-61.

2. Панченко Т.Н. Деятельность с умом, очищенным от мысли? (Л. Витгенштейн и восточная философия) // Современная аналитическая философия. Вып. 3. Сознание и деятельность, 1991. C. $138-167$.

3. Băiaş C. Non-argumentative rhetoric: aspects of Zen rhetoric // Professional Communication and Translation Studies, 2013. Vol. 6 (1-2). P. 35-42.

4. Витгенштейн Л. Философские исследования / пер. с англ. М.: Гнозис, 1994. Ч. І. 612 с.

5. Медведев Н.В. Философия Людвига Витгенштейна и проблемы понимания других культур. Тамбов: Издательский дом ТГУ им. Державина, 2009. 382 с.

6. Рыскельдиева Л.Т. Основы буддийской метафизики «дхармы» // Ученые записки Таврического национального университета им. В.И. Вернадского. Серия «Философия. Культурология. Политология. Социология». 2009. Т. 22 (61), № 2. С. 21-28.

7. Торчинов E.A. Философия буддизма Махаяны. СПб.: Петербургское востоковедение, $2002.320 \mathrm{c}$.

8. D'Amato, M. Why the Buddha Never Uttered a Word // D'Amato M., Garfield J.L., Tillemans T.J. Pointing at the Moon: Buddhism, Logic, Analytic Philosophy. Oxford: Oxford University Press, 2009. $200 \mathrm{p}$.

9. Chang G. The Buddhist Teaching of Totality: The Philosophy of Hwa Yen Buddhism. University Park: The Pennsylvania State Press, 1971. 300 p.

10. Monk R. Ludwig Wittgenstein: The Duty of Genius. Penguin Books, 1991. 154 p.

11. Медведев Н.В. Трансформация философии (К 125 -летию со дня рождения Людвига Витгенштейна) // Философские традиции и современность. 2014. № 1(5). С. 63-80.

12. Vlădutescu S. Communication of Silence at Ludwig Wittgenstein: Linguistic Silence // International Letters of Social and Humanistic Sciences. 2014. № 5. P. 81-86.

13. Garver $N$. The «Silence» of Wittgenstein and Kraus // Interdisciplinary conference on Writing the Austrian Tradition. Toronto, 2000. P. 67-79.

14. Tominage T.T. Ch'an, Taoism and Wittgenstein // Journal of Chinese philosophy. Honolulu, 1983. Vol 10, № 2/3. P. 127-145.

Fedotova Ekaterina Yu. Tambov State University named after G.R. Derzhavin (Tambov, Russian Federation)

DOI: $10.17223 / 1998863 \mathrm{X} / 34 / 37$

COMPREHENSION OF THE PHENOMENON OF SILENSE: WITTGENSTEIN AND EASTERN PHILOSOPHY

Keywords: Wittgenstein, Eastern philosophy, silence, comparative analysis 
The problem of mutual relations between language and world has always been of interest both western and eastern philosophy. In particular, the special attention is still paid to silence which is represented as a specific category of language. It is possible to find plenty of ideas concerning understanding of the phenomenon of silence in the world wide philosophy. However, in our opinion the idea of comparing the visions of two philosophical systems belonging to different cultural traditions and ways of thinking is the most effective. The article presents a comparative analysis of the philosophy of Ludwig Wittgenstein and eastern philosophical systems that represented by Taoism and Buddhism, in their attitude to the phenomenon of silence. The author of the article examines the problem in three main aspects: 1. understanding of philosophy as an activity and defining the role of language in it; 2 . setting apart of showing as a third mode of communication from speaking and silence; 3 . The designation of the specifics of understanding of silence in the context of wittgensteinian and eastern philosophical thought. This research aims to identify similarities and differences in the understanding of the category of silence in two considered philosophical systems. The necessity for such clarification of the results of the hard work of his thought is conditioned by the fact that Wittgenstein's philosophy has had and still continues to exert so strong influence not only on modern Western but also on Eastern philosophy. Silence plays an important role for both Wittgenstein's philosophy and Eastern philosophy. These two ways to practice of silence are not identical in point of fact, but they complement each other. In that way, the philosophy of Wittgenstein not only shows a clear resemblance to the thought of oriental philosophical practices, but it can also be understood as contributing to their understanding. As well as the other way around: understanding of Taoism and Buddhism can be of great help in achieving a better understanding of the philosophy of Wittgenstein.

\section{References}

1. Gorin, A.V. (2001) [The boundaries of language and the language of boundaries. Wittgenstein and Zen]. Put' Vostoka. Problema metodov [The Way of the East. The problem of methods]. Proc. of the Fourth Younth Research Conference on Philosophy, Religion and Culture of the East. St. Petersburg: St. Petersburg Philosopical Society. pp. 57-61. (In Russian).

2. Panchenko, T.N. (1991) Deyatel'nost' s umom, ochishchennym ot mysli? (L. Vitgenshteyn i vostochnaya filosofiya) [Activities with a mind free of thoughts? (L. Wittgenstein and Eastern philosophy)]. In: Bobrova, L.A. (ed.) Sovremennaya analiticheskaya filosofiya [Modern Analytic Philosophy]. Issue 3. pp. 138-167.

3. Băiaş, C. (2013) Non-argumentative rhetoric: aspects of Zen rhetoric. Professional Communication and Translation Studies. 6(1-2). pp. 35-42.

4. Wittgenstein, L. (1994) Filosofskie issledovaniya [Philosophical Investigations]. Translated from German by M. S. Kozlova, Yu.A. Aseev. Moscow: Gnozis.

5. Medvedev, N.V. (2009) Filosofiya Lyudviga Vitgenshteyna i problemy ponimaniya drugikh kul'tur [The philosophy of Ludwig Wittgenstein and the problem of understanding of other cultures]. Tambov: Tambov State University.

6. Ryskeldieva, L.T. (2009) The Foundation of Buddhist "Dharma' Metaphisics". Uchenye zapiski Tavricheskogo natsional'nogo universiteta im. V.I. Vernadskogo. Seriya «Filosofiya. Kul'turologiya. Politologiya. Sotsiologiya»-Scientific Notes of Taurida National V.I. Vernadsky University. Philosophy. Culturology. Political Science. Sociology. 22(61-2). pp. 21-28. (In Russian).

7. Torchinov, E.A. (2002) Filosofiya buddizma Makhayany [The philosophy of Mahayana Buddhism]. St. Petersburg: Peterburgskoe vostokovedenie.

8. D’Amato, M. (2009) Why the Buddha Never Uttered a Word. In: D’Amato, M., Garfield, J.L. \& Tillemans, T.J. Pointing at the Moon: Buddhism, Logic, Analytic Philosophy. Oxford: Oxford University Press.

9. Chang, G. (1971) The Buddhist Teaching of Totality: The Philosophy of Hwa Yen Buddhism. University Park: The Pennsylvania State Press.

10. Monk, R. (1991) Ludwig Wittgenstein: The Duty of Genius. Penguin Books.

11. Medvedev, N.V. (2014) Transformatsiya filosofii (K 125-letiyu so dnya rozhdeniya Lyudviga Vitgenshteyna) [Transformation of philosophy. The 125th anniversary of the birth of Ludwig Wittgenstein]. Filosofskie traditsii i sovremennost'. 1(5). pp. 63-80.

12. Vlădutescu, S. (2014) Communication of Silence at Ludwig Wittgenstein: Linguistic Silence. International Letters of Social and Humanistic Sciences. 5. pp. 81-86.

13. Garver, N. (2000) The "Silence" of Wittgenstein and Kraus. Interdisciplinary Conference on Writing the Austrian Tradition. Toronto. pp. 67-79.

14. Tominage, T.T. (1983) Ch'an, Taoism and Wittgenstein. Journal of Chinese Philosophy. 10(2/3). pp. 127-145. DOI: 10.1111/j.1540-6253.1983.tb00277.x 